\title{
Original article \\ Acute fatigue effects on ground reaction force of lower limbs during countermovement jumps
}

\author{
Carlos Gabriel Fábrica \\ Paula V. González \\ University of the Republic of Uruguay, Uruguay \\ Jefferson Fagundes Loss \\ Federal University of Rio Grande do Sul, Brazil
}

\begin{abstract}
Parameters associated with the performance of countermovement jumps were identified from vertical ground reaction force recordings during fatigue and resting conditions. Fourteen variables were defined, dividing the vertical ground reaction force into negative and positive external working times and times in which the vertical ground reaction force values were lower and higher than the participant's body weight. We attempted to explain parameter variations by considering the relationship between the set of contractile and elastic components of the lower limbs. We determined that jumping performance is based on impulsion optimization and not on instantaneous ground reaction force value: the time in which the ground reaction force was lower than the body weight, and negative external work time was lower under fatigue. The results suggest that, during fatigue, there is less contribution from elastic energy and from overall active state. However, the participation of contractile elements could partially compensate for the worsening of jumping performance.
\end{abstract}

Keywords: biomechanics, muscle rigidity, task performance, fatigue

Resumo- - Estudo do efeito agudo da fadiga na força de membros inferiores durante saltos com contramovimento." Parâmetros associados com o desempenho do salto contramovimento foram identificados a partir de registros da força vertical em condições de fadiga e não fadiga. Quatorze variáveis foram definidas dividindo a força de reação vertical do solo em valores negativos e positivos de trabalho externo e o tempo em que os valores de força vertical foi menor e maior do que o peso corporal do indivíduo. As variações dos parâmetros foram avaliadas considerando a relação entre conjunto de elementos contráteis e elásticos nos membros inferiores. Determinou-se que o desempenho é baseado na otimização do impulso e não em um valor instantâneo da força; o tempo em que a força de reação do solo foi menor do que o peso corporal e o tempo de trabalho externo negativo são mais baixos sob fadiga. Os resultados sugerem que durante a fadiga há uma menor contribuição da energia elástica e do estado ativo de forma global, mas a participação de elementos contráteis poderia compensar parcialmente a queda de desempenho.

Palavras-chaves: biomecânica, rigidez muscular, análise e desempenho de tarefas, fadiga

Resumen-"Estudio del efecto de la fatiga aguda en la fuerza del miembros inferiores durante saltos con contramovimiento." Se identificaron parámetros asociados con el desempeño de saltos con contramovimiento a partir de registros de fuerza vertical en condiciones de fatiga y no fatiga. Catorce variables fueron definidas dividiendo la componente vertical de la curva de fuerza de reacción del suelo en valores negativos y positivos de trabajo externo y tiempo en que los valores de fuerza resultaron menores o mayores que el valor del peso del individuo. Las variaciones de los parámetros fueron evaluadas considerando la relación entre el conjunto de elementos contráctiles y elásticos en los miembros inferiores. Se determinó que el desempeño está basado en la optimización del impulso y no en un valor instantáneo de fuerza; el tiempo en que la fuerza de reacción del suelo fue menor que el peso corporal y el tiempo de trabajo externo negativo resultaron más bajos en fatiga. Los resultados sugieren que durante la fatiga hay una menor contribución de la energía elástica y del estado activo de forma global, pero la participación de elementos contráctiles podría compensar parcialmente la caída en el desempeño.

Palabras claves: biomecánica, rigidez muscular, análisis y desempeño de tareas, fatiga

\section{Introduction}

Reaching maximum possible height during a vertical jump is crucial in various sports activities such as volleyball (Bosco, Komi, \& Ito, 1981), soccer (Fábrica, Alonso, Rey,
Polero, \& Berreta, 2008), and basketball (Zib \& Lidor, 2010). Moreover, the height achieved in different types of vertical jumps has commonly been used to estimate one's physical fitness relative to health (Bosco et al., 1981; Fábrica et al., 2008; Komi \& Bosco, 1978). 
A countermovement jump (CMJ) is a vertical jump commonly used in sports evaluation that includes a countermovement phase (Bobbert, 1996; Bobbert \& Soest, 1994; Fábrica et al., 2008). The CMJ technique is more similar to the jumps performed during sports practice than other jumps that do not involve countermovement and are also used in assessment protocols, for example, the squat jump (Bobbert, 1996; Fábrica et al., 2008).

Performance improvement during CMJ has been related to mechanical aspects and to variations in muscle activity. Among these aspects, the ones which stand out are the role of the elastic energy stored in the series elastic elements (SEE) (Bosco et al., 1981; Kubo et al., 2007), the pre-activation of the contractile elements (CE) (Horita, Komi, Nicol, \& Kyröläinen, 2002; Kyröläinen, Finni, Avela, \& Komi, 2003; Moritani, Oddsson, \& Thorstensson, 1991), and the contribution of the stretch reflex (Komi \& Gollhofer, 1997). As these aspects are closely related and influence each other, it is difficult to determine which of them play a central role in the performance of CMJ.

For decades, much research has discussed the way in which the ability of generating force during a CMJ is associated with active mechanisms and regulation of stiffness (Kuitunen, 2010). Given that stiffness of the muscletendon units (MTU) is determined by the elastic properties of the CE and SEE (Herzog, 2000), a change in the forcelength relationship of the MTU can be achieved by a different relative deformation of one or another component. These deformations are associated with the activity and the ability of CE strength (Herzog, 2000), both of which vary considerably in different conditions such as acute muscle fatigue (Avela, Kyröläinen, Komi, \& Rama, 1999; Chin, Balmore, \& Allen, 1997; Kuitunen, 2010; Windhorst, 2007). Acute fatigue determines metabolic changes (Green, 1997), which could contribute to the decrease of the force capacity in a direct way by altering the excitation-contraction coupling process (Chin et al., 1997), or in an indirect way, among other things, by decreasing sensitivity to the stretch reflex (Avela et al., 1999; Windhorst, 2007).

Since under fatigue conditions, the MTU activation level is altered during the CMJ (Rodacki, Fowler, \& Bennett, 2002), it is expected that changes in stiffness will occur in this condition. As a consequence, the contribution of elastic energy stored and returned by all SEE of the lower limbs could be altered during acute state of fatigue. There are backgrounds which established that, after maximum exercises that involve countermovements, an increase in muscular activation occurs (Strojnik \& Komi, 1998). This situation produces a relative increase in the set CE stiffness and contributes to the accumulation of more energy during the negative external working time of the set SEE during a CMJ. However, it is not clear if there is any mechanism that allows an individual to maintain a good performance when doing maximum CMJs under fatigue conditions.

Various biomechanical approaches, such as simulations (Bobbert, 1996), electromyographic analysis (Rodacki et al., 2002), and ground reaction force platform recordings
(Dowling \& Vamos, 1993), have been used to identify variables associated with the CMJ performance. Although all of them have been useful in some way, only the same vertical ground reaction force recordings involve the same performance (Dowling \& Vamos, 1993). Thus, the vertical ground reaction force-time recordings contain kinetic and temporal information that can be objectively used in the analysis of the causes that determine the performance during CMJs (Dowling \& Vamos, 1993). In this way, previous studies have suggested that the vertical ground reaction force application pattern is more important than any other instantaneous value (e.g., the maximum vertical ground reaction force value) (Dowling \& Vamos, 1993).

The identification of descriptive parameters of the vertical ground reaction force pattern associated with the CMJ performance before and after a fatigue protocol will allows us to discuss the SEE and CE set participation of the lower limbs. The main purpose of this study is to discuss the overall participation of the SEE and CE set of the lower limbs during CMJs performed in acute fatigue conditions. Lower limbs are represented as a single spring that encompasses the SEE set in a series of CE of the lower limbs. The vertical ground reaction force recordings obtained during maximum $\mathrm{CMJ}_{\mathrm{s}}$ in resting stare and under fatigue conditions were considered. We divided the vertical ground reaction force recordings into external working time (positive and negative) and the time during which the vertical ground reaction force recording results were lower or higher than the participant's body weight (Cavagna, 2006). Fourteen variables were defined from the obtained values and compared in each condition.

\section{Methods}

\section{Participants}

Ten healthy and active participants with previous experience in vertical jump tests voluntarily participated in this study (as shown in Table 1). At the time of the study, none of them had history of neuromuscular or musculoskeletal impairments that could affect their jumping technique. The protocol and informed consent were approved by the Ethics Committee of Facultad de Medicina, Universidad de la República, Uruguay (approval number 07114000176409) and all participants signed the informed consent form.

\section{Experimental procedures}

Each participant was instructed to make a series of maximum CMJs on a force platform (AMTI OR6-5) (Advanced Mechanical Technology Inc., Watertown, Massachusetts). As a result, ground reaction forces were obtained on a frequency of $1000 \mathrm{~Hz}$. Participants initiated a jump from an upright standing position, then making a countermovement until they reached a knee flexion angle of 
Table 1. Physical characteristics of the individuals who participated in the study. BMI (body mass index), LL (leg length).

\begin{tabular}{cccccc}
\hline Participant & $\begin{array}{c}\text { Age } \\
(\text { years })\end{array}$ & $\begin{array}{c}\text { Body mass } \\
(\mathbf{k g})\end{array}$ & $\begin{array}{c}\text { Height } \\
(\mathbf{m})\end{array}$ & $\begin{array}{c}\text { BMI } \\
\left(\mathbf{k g} / \mathbf{m}^{\mathbf{2}}\right)\end{array}$ & $\begin{array}{c}\text { LL } \\
(\mathbf{m})\end{array}$ \\
\hline $\mathbf{1}$ & 22.0 & 71.00 & 1.73 & 23.70 & 0.83 \\
$\mathbf{2}$ & 23.0 & 75.00 & 1.80 & 23.15 & 0.90 \\
$\mathbf{3}$ & 19.0 & 70.00 & 1.70 & 24.22 & 0.80 \\
$\mathbf{4}$ & 24.0 & 73.50 & 1.77 & 23.32 & 0.88 \\
$\mathbf{5}$ & 25.0 & 77.10 & 1.85 & 22.51 & 0.92 \\
$\mathbf{6}$ & 23.0 & 68.00 & 1.69 & 23.78 & 0.83 \\
$\mathbf{7}$ & 24.0 & 71.20 & 1.75 & 23.27 & 0.87 \\
$\mathbf{8}$ & 26.0 & 74.30 & 1.73 & 24.80 & 0.84 \\
$\mathbf{9}$ & 22.0 & 75.20 & 1.81 & 22.93 & 0.93 \\
$\mathbf{1 0}$ & 27.0 & $\mathbf{6 8 . 0 0}$ & 1.67 & 24.37 & 0.80 \\
mean $\mathbf{+ S D}$ & $\mathbf{2 3 . 5} \pm \mathbf{2 . 3}$ & $\mathbf{7 2 . 2 \pm 3 . 1}$ & $\mathbf{1 . 7 5} \mathbf{0 . 0 6}$ & $\mathbf{2 3 . 6 1 \pm 0 . 7 1}$ & $\mathbf{0 . 8 6} \pm \mathbf{0 . 0 5}$ \\
\hline
\end{tabular}

$90^{\circ}$. The angle variability during the jumps was controlled by film/video analysis. Knee flexions that varied more than $5^{\circ}$ relative to the reference pre-established angle $\left(90^{\circ}\right)$ were discarded. Five jumps were selected for each participant. Each maximum CMJ series was repeated twice for each of the two conditions (under fatigue and resting state), allowing us to analyze a total of 50 jumps in each condition. Fatigue condition was determined by using a test of consecutive maximal vertical jumps (Bosco et al., 1983). Each participant was instructed to jump as high as possible for 60 seconds using the CMJ technique by bending his or her knees at about $90^{\circ}$.

The interval between the first series of jumps and the fatigue protocol, and between the latter and the second series of jumps lasted five minutes. The number of vertical jumps performed during this period varied between 50 and 63 . In high intensity and short duration fatigue protocols, such as the one herein used, an immediate decrement in performance occurs. Partial recover takes one hour or two after cessation of the exercise (Nicol, Avela, \& Komi, 2006). Participants likely experienced acute fatigue by the second series of jumps.

Fatigue analysis was conducted using the mean mechanical power recorded during the vertical jumps (W) (Bosco, 1983). Power was determined every 15 seconds, and comparison of mechanical power between the first and the last 15 seconds of jumps was considered the fatigue marker in this study. The fatigue marker was determined by the equation:

$$
\mathrm{W}=\mathrm{g}^{2} \cdot \mathrm{t}_{\mathrm{v}} 60\left[4 \mathrm{n}\left(60-\mathrm{t}_{\mathrm{v}}\right)\right]^{-1}
$$

where $g$ is the acceleration of gravity, $t_{v}$ is the total flight time over 60 seconds, and $n$ the number of jumps. This procedure has been tested several times with physiological markers, such as lactate concentration (Fisher, 2010).

\section{Data processing}

The vertical ground reaction force component (Fy) was analyzed, while the other force components were rejected after confirming that their magnitude was less than $5 \%$ of the vertical component. Fy data were exported to MATLAB ${ }^{\circledR}$ and filtered using a Butterworth third order filter with a maximum frequency determined by a residual analysis (Winter, 1990).

The vertical velocity of the participant's center of mass (CM) was determined according to the following equation (Komi \& Bosco, 1978):

$$
\mathrm{V}_{\mathrm{v}}=1 / 2 \cdot \mathrm{T}_{\mathrm{air}} \cdot \mathrm{g}
$$

with $g$ being the gravity acceleration $\left(9.81 \mathrm{~m} / \mathrm{s}^{2}\right)$ and Tair the flying time after the initiation of each jump. The latter was directly determined using the Fy curve.

The height reached in the jump (Hmax) was calculated as:

$$
\mathrm{H}_{\max }=\mathrm{V}_{\mathrm{v}}^{2} \cdot(2 \mathrm{~g})^{-1}
$$

The Fy curve was divided into two parts following two different criteria, as described in Cavagna (2006) and shown in Figure 1. We consider the time in which the Fy value was lower or higher relative to the body weight of the participant $(\mathrm{P})$, and the period of positive or negative external work. The period of time of the second criterion corresponded with the downward and upward phase of the CM in each jump. Figure 2 shows how vertical ground reaction force curves were divided graphically for further analysis.

In order to determine the initiation and the end of the positive/negative external work, we calculated the CM kinetic energy (EK) and gravity potential energy (EP) (Cavagna, 2006), using velocity and vertical displacement. In order to calculate $\mathrm{P}$ value, $\mathrm{P}$ was subtracted from Fy. Then, the result was divided by the participant's body mass. Lastly, velocity and displacement were obtained by integrating their curves. Based on this criteria, maximum $\left(\mathrm{F}_{\max }\right)$ and minimum $\left(\mathrm{F}_{\min }\right)$ vertical ground reaction force values were normalized using participants weight, sample of four time intervals and propulsions, so that temporary and force-time relationship changes could be associated to fatigue. 


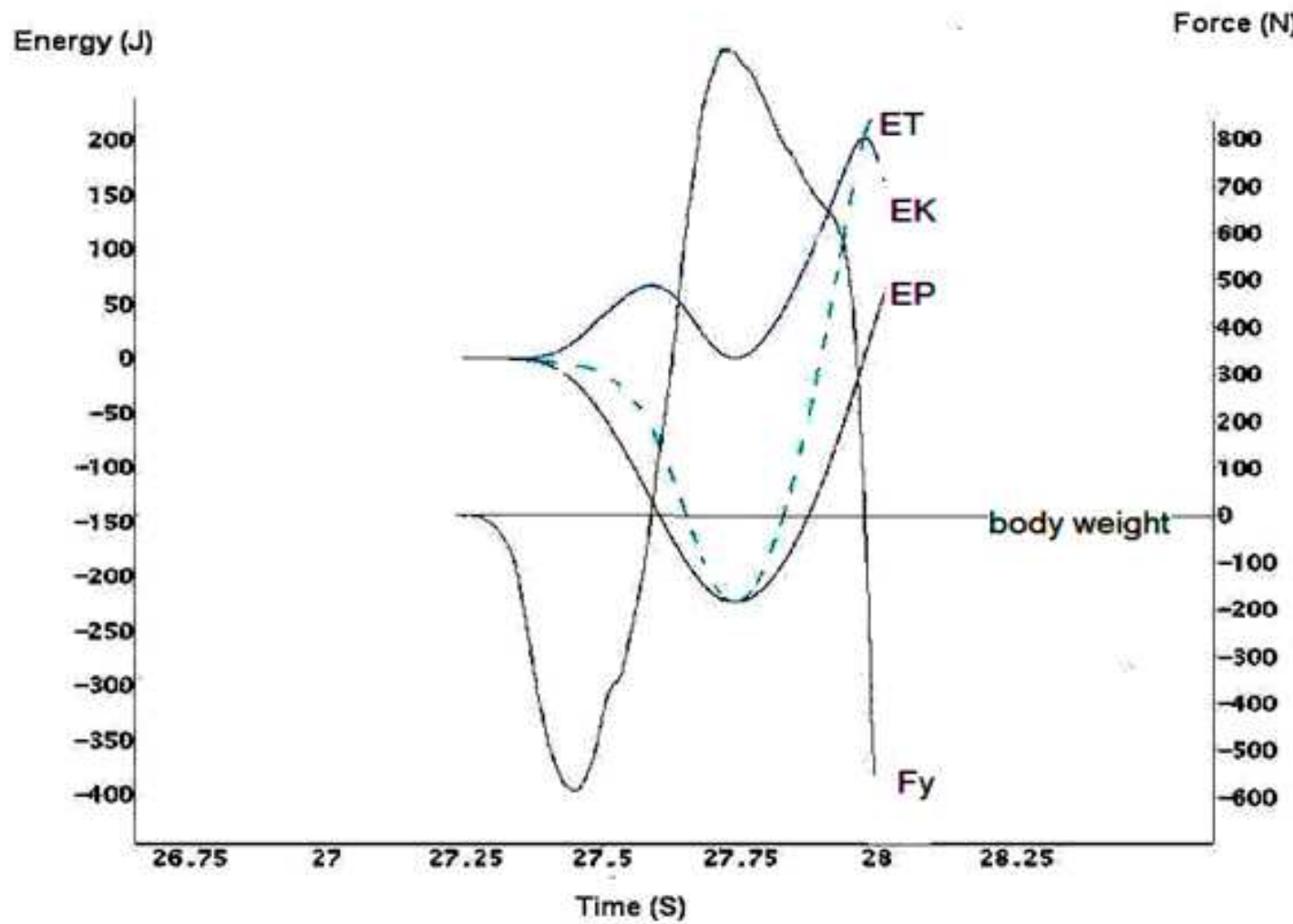

Figure 1. The mechanic energy variations considered to determine the positive and negative external working times, and the relation between the vertical force recording and the subject's weight during a CMJ. EK: kinetic energy, EP: potential energy and ET: total mechanic energy.

The beginning of the jump until Fy was equaled to P; the time in which the SEE was stretched $\left(\mathrm{t}_{1}\right)$; the end of $\mathrm{t}_{1}$ until the moment when the participant took off; the time in which the SEE was compressed $\left(\mathrm{t}_{2}\right)$, from the beginning of the jump until the moment when $\mathrm{F}_{\max }$ occurred, which corresponded to the negative external mechanic working time $\left(\mathrm{t}_{3}\right)$; and, finally, from the moment when Fmax occurred until the moment of take off, which corresponded to the positive external mechanic working time $\left(\mathrm{t}_{4}\right)$.

Considering these time intervals, we calculated the impulsion for each interval (integral of the area under the vertical force-time curve) and named them accordingly to the time interval to which they corresponded. Hence, impulsion $1\left(\operatorname{Imp}_{1}\right)$ corresponded with the one that occurred during the period in which the SEE stretched; impulsion 2 $\left(\operatorname{Imp}_{2}\right)$ occurred when SEE compressed; impulsion $3\left(\operatorname{Imp}_{3}\right)$ occurred during the negative external mechanic working time; and impulsion $4\left(\mathrm{Imp}_{4}\right)$ occurred during the positive external mechanic working time.

On the other hand, some temporal and impulse relations were considered: $\mathrm{t}_{1} / \mathrm{t}_{2}, \mathrm{t}_{3} / \mathrm{t}_{4}, \operatorname{Imp}_{1} / \operatorname{Imp}_{2}$, and $\operatorname{Imp}_{2} / \mathrm{Imp}_{3}$. The first ratio corresponded to the temporal relation between extension and compression of the system (according to the mass-spring model); the second ratio corresponded to the relationship between the negative and positive working times (Cavagna, 2006). To ascertain that the spring corresponded to what happened in the lower limb MTU extensors during jumping, we considered that SEE was stretched during $t_{1}$. Figure 2 shows graphically the times considered in this work.

\section{Statistic analysis}

We compute the mean mechanical power from every 15 seconds of maximal vertical jumps, and divided the 60 seconds of the fatigue protocol into four periods. Thus, a one-way repeated-measure ANOVA and standard contrasts post hoc test were carried out to confirm presence of fatigue. For each jumping series, the mean and the standard deviation of each variable were calculated, and the data were fitted to a normal distribution through the Shapiro-Wilks test. To determine which variable was associated with the jumping height in conditions of fatigue and resting state, a Pearson correlation test was performed $(p<0.05)$ for each variable with respect to the height reached in each condition. Finally, differences of obtained values for the variables in each condition were submitted to a paired sample t-test $(p<0.05)$.

\section{Results}

Results shows that the mean mechanical power was significantly affected by the analyzed period $\left(F_{3,45}=354.8\right.$, $p \leq 0.001)$. The mean mechanical power of every 15 seconds 

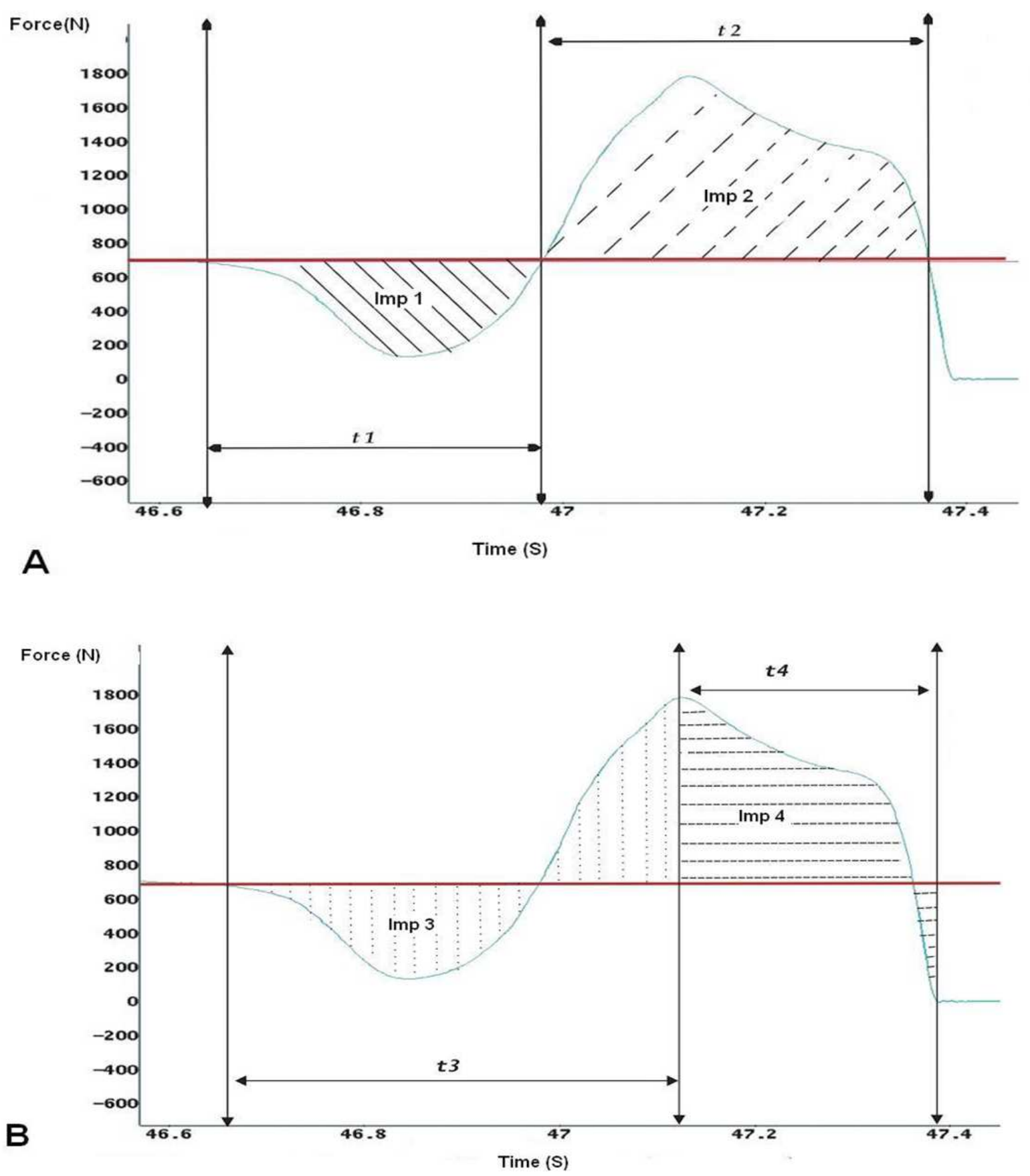

Figure 2. A) The curve is divided by the relation between Fy and P. B) the curve is divided in function of the positive or negative external mechanic working times. The nomenclature for the times and impulses are explained in the text.

of maximal vertical jumps showed a clear downward trend, with values of $20.5,17.9,14.5$ and $11.6 \mathrm{~W} / \mathrm{kg}$ for periods 0 $15 \mathrm{~s}, 15-30 \mathrm{~s}, 30-45 \mathrm{~s}$ and $45-60 \mathrm{~s}$, respectively. Contrast analysis revealed that mean mechanical power of the second period was significantly lower than the first $\left(F_{1,15}=140.7\right.$, $p \leq 0.001)$; the third period was significantly lower than the second $\left(F_{1,15}=115.1, p \leq 0.001\right)$; and the fourth significantly lower than third $\left(F_{1,15}=203.5, p \leq 0.001\right)$.

During the jumps, the reached heights in both conditions were significantly different $(p<0.05)$; the results of the t-test for the heights are shown in the first row of Table 4. The correlation coefficients of the twelve variables with the maximum height reached are shown in Tables 2 and 3. In these tables, the times and temporal relations (Table 2) and the force and impulsion values considered (Table 3) are shown separately.

Table 2 illustrates that the correlated temporal variables with the height were different in each condition. During resting state, the times correlated with the height were the one corresponding to the period of time in which the system 
Table 2. The table shows the correlation coefficients between the maximum height reached in $\mathrm{CMJ}\left(\mathrm{H}_{\mathrm{mx}}\right)$ before the fatigue protocol (NF) and with muscular fatigue (F), and the time and temporal relations considered in the analysis. The asterisks (*) indicate the existence of significant correlations $(p<0.05)$.

\begin{tabular}{llllllll}
\hline \multicolumn{6}{c}{ Correlation of times and temporal relations with height } \\
\hline & $\mathrm{t}_{1}$ & $\mathrm{t}_{2}$ & $\mathrm{t}_{3}$ & $\mathrm{t}_{4}$ & $\mathrm{t}_{1} / \mathrm{t}_{2}$ & $\mathrm{t}_{3} / \mathrm{t}_{4}$ \\
$\mathrm{H}_{\max } . \mathrm{NF}$ & 0.30 & $0.69^{*}$ & 0.17 & $0.77^{*}$ & -0.36 & -0.59 \\
$\mathrm{H}_{\text {max }} . \mathrm{F}$ & $0.72 *$ & 0.39 & 0.30 & 0.40 & 0.60 & -0.35
\end{tabular}

Table 3. The correlation coefficients between the maximum height reached in $\mathrm{CMJ}\left(\mathrm{H}_{\max }\right)$ before the fatigue protocol (NF) and in presence of muscular fatigue $(\mathrm{F})$ and the kinetic values considered in the study. The asterisks $(*)$ and $(* *)$ indicate the existence of significant correlations with $p<0.05$ and $p<0.01$ respectively.

\begin{tabular}{lcccccccc}
\hline \multicolumn{7}{c}{ Correlation of forces and impulses with height } \\
\cline { 2 - 8 } & $\mathrm{F}_{\text {min. }}$ & $\mathrm{F}_{\max } \cdot$ & $\mathrm{Imp}_{1}$ & $\mathrm{Imp}_{2}$ & $\mathrm{Imp}_{3}$ & $\mathrm{Imp}_{4}$ & $\mathrm{Imp}_{1} / \mathrm{Imp}_{2}$ & $\mathrm{Imp}_{3} / \mathrm{Imp}_{4}$ \\
\hline $\mathrm{H}_{\max } . \mathrm{NF}$ & 0.04 & $0.68^{*}$ & $0.63^{*}$ & 0.55 & 0.46 & 0.59 & 0.45 & -0.39 \\
$\mathrm{H}_{\text {max }} . \mathrm{F}$ & -0.09 & 0.60 & 0.57 & $0.84^{* *}$ & $0.70^{*}$ & $0.77^{* *}$ & 0.15 & $-0.66^{*}$ \\
\hline
\end{tabular}

was being shortened $\left(\mathrm{t}_{2}\right)$ and the period of time of the positive work $\left(\mathrm{t}_{4}\right)$. In fatigue conditions, the time correlated with the height was the period in which the system stretched $\left(t_{1}\right)$.

Correlations between force and impulsion, and correlations between jumping height also showed differences in each condition. One result to highlight is that, as well as for the Imp, $\mathrm{F}_{\text {max }}$ was associated with the height only during the resting condition. Under fatigue conditions, important results were found: the high significant correlation between the reached height and the achieved impulsion during the stretch period of the system's elastic elements $\left(\operatorname{Imp}_{2}\right)$, the impulsion achieved during the negative external work $\left(\operatorname{Imp}_{3}\right)$, the impulsion achieved during the positive external work $\left(\operatorname{Imp}_{4}\right)$, and the relationship between this two last parameters $\left(\operatorname{Imp}_{3} / \operatorname{Imp}_{4}\right)$.

Table 4 shows the $t$-test results which intended to analyze the changes due to fatigue conditions in selected variables. The only variables that showed a significant change were the time during which the system was stretched $\left(\mathrm{t}_{1}\right)$ and the time during which the negative external work $\left(t_{3}\right)$ occurred, both revealing lower results under fatigue conditions.

\section{Discussion}

The jump heights reached in the CMJ during the resting state $(0.31 \pm 0.06 \mathrm{~m})$ and under fatigue $(0.29 \pm 0.06 \mathrm{~m})$ were comparable to those found in studies in which participants used similar jumped technique to our study (Hortobagi, Lambert, \& Kroll, 1991; Rodacki et al., 2002). The significant
Table 4. Results of the paired samples $t$ test for the $\mathrm{H}_{\max }$ of the jumps and some variables defined in the study. Asterisks in the second column indicates variables which showed significant differences in one condition relative to the other $(p<0.05)$.

\begin{tabular}{|c|c|c|}
\hline Variables $($ mean \pm SD) & NF & $\mathbf{F}$ \\
\hline $\mathrm{F}_{\max } \cdot(\mathrm{m})$ & $1700 \pm 162$ & $1733 \pm 144$ \\
\hline $\operatorname{Imp}_{1}$ (N.m) & $83 \pm 20$ & $86 \pm 23$ \\
\hline $\operatorname{Imp}_{2}$ (N.m) & $251 \pm 43$ & $259 \pm 43$ \\
\hline $\operatorname{Imp}_{3}$ (N.m) & $179 \pm 21$ & $177 \pm 21$ \\
\hline $\operatorname{Imp}_{4}$ (N.m) & $155 \pm 45$ & $168 \pm 45$ \\
\hline $\operatorname{Imp}_{1} / \operatorname{Imp}_{2}$ & $0.33 \pm 0.06$ & $0.33 \pm 0.05$ \\
\hline $\mathrm{Imp}_{3} / \mathrm{Imp}_{4}$ & $1.23 \pm 0.29$ & $1.11 \pm 0.23$ \\
\hline $\mathrm{t}_{1}(\mathrm{~s})$ & $0.36 \pm 0.06^{*}$ & $0.32 \pm 0.05$ \\
\hline $\mathrm{t}_{2}(\mathrm{~s})$ & $0.40 \pm 0.06$ & $0.39 \pm 0.06$ \\
\hline
\end{tabular}

decrease of the maximum height reached in the CMJ under an acute fatigue condition (Table 4) was expected. Previous studies have associated this performance decrement with changes in the capacities of different muscles groups (Kuitunen, 2010; Rodacki et al., 2002). Such changes can be attributed to the combined effect of the ability of using elastic energy and the variation of contractile activity (Horita et al., 2002; Komi \& Gollhoffer 1997; Kubo et al., 2007; Kyröläinen et al., 2003; Moritani et al, 1991).

It seems clear that the interaction between the CE and SEE of the MTU is highly specific, depending on the task done and the contraction conditions (Isikawa \& Komi, 2008; Kawakami \& Fukunaga, 2006). Although this interaction could vary for each muscle group (Kuitunen, 2010), we believed that analyzing the whole system and considering the set of SEE and CE of lower limbs was a good alternative for describing the overall mechanics of jumping and its possible variations. The parameters associated with the performance of the CMJ were identified from the vertical ground reaction force recordings during fatigue and resting conditions. We attempted to explain the parameter variations for each condition by considering the interaction of the set established between the CE and SEE of the MTU of lower limbs.

Previously, Dowling and Vamos (1993) studied eighteen variables defined from the vertical ground reaction force recording. In their study, the criterion for dividing the vertical force-time curve was not considered. Nevertheless, although differently labeled, some of the investigated variables $\left(t_{1}, t_{2}\right.$, $\mathrm{t}_{4}, \mathrm{~F}_{\text {min }}, \mathrm{F}_{\text {max }}$, and $\operatorname{Imp}_{1} / \mathrm{Imp}_{2}$ ) were common in both studies.

Variables correlated with height were affected differently during fatigue and resting state (Tables 2 and 3 ). The significant correlations of times $t_{2}$ and $t_{4}$ during the resting condition partially coincide with values reported by Dowling and Vamos (1993). They found a significant correlation between height and the phase which corresponds to $t_{4}$, but 
not with the phase corresponding to $\mathrm{t}_{2}$. On the other hand, we saw that in fatigue conditions, the only time correlated with height was $t_{1}$. The correlation between heights and time could indicate that during the resting state the determinant of the performance during a CMJ occurs during the phase of positive external work. In acute fatigue conditions, however, the time during which the set of SEE stretches occurs primarily for the CMJ performance.

Notwithstanding, as in the CMJ performed without a high degree of fatigue, the reached height was higher than values found for squat jump under similar conditions (Fábrica et al., 2008). Additionally, it is clear that, during the resting state, the external negative working phase has implications over the external positive working phase. The literature offers different explanations of how negative work could affect the CMJ performance: allowing the muscle structures to have an optimum length at the beginning of the contraction (Ingen Schenau, 1984); giving the necessary time for the muscles to reach a highly active state value (Bobbert, 1996); storing energy in the elastic elements (Kubo et al., 2007); favoring the participation of the pre-activation (Horita et al., 2002; Kyröläinen et al., 2003; Moritani et al., 1991); and contributing to the stretch reflex (Komi \& Gollhoffer, 1997). During the support phase time of a jump, all of these considerations are associated with interactions between the set of CE and set of SEE of lower limbs.

The results of the $t$-tests (Table 4) showed that of the fourteen variables considered in this work, $t_{1}$ and $t_{3}$ would be the more suitable to discuss the behavior of the MTU in each condition during the CMJ. The decrease of $t_{1}$ observed in the fatigue conditions indicates that the time during which the mass-spring system is being charged (McMahon \& Cheng, 1990) varies with the fatigue degree, and it could suggest that there is a decrease in the relative contribution of the elastic energy stored in the set of SEE. However, this decrement could be an indicator of changes at another level, for example, a decrease in the global activation state (Bobbert, 1996) or alterations in the participation of the stretch reflex of leg extensors (Windhorst, 2007; Zhang \& Zevrymer, 2001). The latter aspect is based on the fact that, during maximum power jumps and reduced ground contact time, the system's general stiffness increases (leg stiffness) (Hobara, Kanouse, $\&$ Suzuki, 2007). We assume that the decrease of $t_{1}$ under fatigue leads to reduced utilization of the elastic energy and lower magnitude of the active state for the next jumping phase; however, the decrease could also strengthen the stretch reflex.

Additionally, we found that $t_{3}$ variable decreased significantly under fatigue conditions, while $\mathrm{t}_{4}$ did not. We assumed that the displacement of the CM was the same in each condition. This difference in $t_{3}$ is coherent with results found and discussed for $t_{1}$. A minor accumulation of elastic energy in the set of SEE would determine its reduced contribution during $t_{4}$. Thus, for the purpose of reaching a good performance during an equal period of time $\left(\mathrm{t}_{4} \mathrm{did}\right.$ not show significant differences), a major participation of the set of CE would be necessary. This participation could be favored by a major participation of the stretch reflex in leg extensors during $t_{3}$. Supporting this idea, the role of the stretch reflex under fatigue has been shown to reach the same level of force in fatigue when the electromyographic signal amplitude increases (Zhang \& Zevrymer, 2001). This aspect could be better understood if a new study were conducted, one including electromyographic analysis of the main muscles participating in jumps. However, herein, the results of the ground reaction force and impulsion analysis were important elements for the discussion about the role general elastic energy and the stretch reflex play, under acute fatigue, on the height reached during CMJ.

The maximum vertical ground reaction force recording, which various authors have associated with good performance, was correlated with height only during the resting state $(r=0.68)$. Dowling and Vamos (1993) also found a significant correlation between these variables $(r=0.59)$ in $\mathrm{CMJ}$ during resting state. Considering that in real conditions the vertical jumps are executed with a certain degree of muscle fatigue, $\mathrm{F}_{\max }$ may not be a good predictor of the CMJ performance. The fact that $\mathrm{F}_{\max }$ is not a determinant element of the jumping height under fatigue is consistent with the significant decrease that $\mathrm{t}_{3}$ showed in this condition, as it indicates that the maximum vertical ground reaction force peak that the participant makes against the ground occurs relatively before the moment of take off.

The correlation values found for the impulsions in the different periods of time support the idea that CMJ performance is based on impulsion optimization and is not necessary for some instantaneous values of force or power (Dowling \& Vamos, 1993). While under resting state, the Imp showed a significant correlation with the jumping height, under fatigue significant correlations were found for $\operatorname{Imp}_{2}, \operatorname{Imp}_{3}, \operatorname{Imp}_{4}$, and the relation of $\operatorname{Imp}_{3} / \operatorname{Imp}_{4}$. The significant correlation of the $\operatorname{Imp}_{1}$ with the height under resting state added to the fact that $t_{1}$ and $F_{\text {min }}$ did not show a significant correlation with the height in that condition. This lack of correlation suggests that the shape of the vertical ground reaction force curve during the first part of negative work $\left(t_{1}\right)$ is a determinant of what happens in the next phase. This latter aspect rests on the fact that $t_{2}$ and $t_{4}$ were significantly correlated with the reached height under the resting state. The shape of the vertical ground reaction force curve at the beginning of the negative work in fatigue would be determined by the active participation of the set of CE. This participation would be influenced by the pre-activation as well as the stretch reflex, as both aspects have an influence on the force exerted during $\mathrm{t}_{1}$ and $\mathrm{t}_{3}$ (Windhorst, 2007). This reasoning is consistent with previous studies' results, which established that, in acute fatigue conditions, there are changes in both types of activation (Kuitunen, 2010). The significant correlations with the height found for $\operatorname{Imp}_{2}, \operatorname{Imp}_{3}$, $\mathrm{Imp}_{4}$ and, mainly, for the relation of $\operatorname{Imp}_{3} / \mathrm{Imp}_{4}$ during fatigue may indicate that important changes exist in the participation of the set of CE and set of SEE in each condition.

The negative correlation between the ratio of the 
impulsion achieved during the negative and positive work $\left(\mathrm{Imp}_{3} / \mathrm{Imp}_{4}\right)$ and the height of the jump, as well as the lack of significant correlations between the jump height with the periods of time in each working phase and the force peaks, indicate that the optimization of the product of vertical force-time during the positive work is essential to achieve good performance during a CMJ under fatigue. However, none of these variables would stand out in this condition. These results are consistent with the idea that the best predictor of a CMJ performance is a combination of the maximum vertical ground reaction force and the length of the positive power phase (Dowling \& Vamos, 1993), which coincide with the period of time $t_{4}$. As it was previously outlined, under acute fatigue, the time during which the set of SEE are stretched is particularly important in the CMJ performance. These aspects, in addition to those discussed for the impulsions, suggest that in CMJ done under acute fatigue conditions, there is an optimization of the product vertical force-time during the positive working time favored by the stretch reflex participation of leg extensors, which could partly compensate for the fatigue effects.

In conclusion, the results of our study suggest that, during fatigue, elastic energy and active state contribute to a less degree to the overall jumping performance. However, the participation of contractile elements could partially compensate for the decrease in such performance.

\section{References}

Arteaga, R., Dorado, C., Chavarren, J., \& Calbet, J. (2000). Reliability of jumping performance in active men and women under different stretch loading conditions. Journal of Sports Medicine and Physical Fitness, 40, 26-34.

Ashley, C., \& Weiss, L. (1994). Vertical jump performance and selected physiological characteristics of women. The Journal of Strength and Conditioning Research, 8, 5-11.

Avela, J., Kyröläinen, H., Komi, P. V., \& Rama, D. (1999). Reduced reflex sensitivity persist several days after long-lasting stretchshortening cycle exercise. Journal of Applied Physiology, 86, 1292-1300.

Biewener, A., \& Daley, M. A. (2007). Unsteady locomotion: Integrating muscle function with whole body dynamics and neuromuscular control. Journal of Experimental Biology, 210, 2949-2960.

Bobbert, M. F., \& Soest, V. (1994). Effects of muscle strengthening on vertical jump height: A simulation study. Medicine \& Science in Sports \& Exercise, 26, 1012-1020.

Bobbert, M. F. (1996). Why is countermovement jump height greater than squat jump height? Medicine \& Science in Sport \& Exercise, 28(11), 1402-1412.

Bobbert, M. F., \& Casius, L. (2005). Is the effect of a countermovement on jump height due to active state development? Medicine \& Science in Sport \& Exercise, 37(3), 440-445.

Bosco, C., Komi, P. V., \& Ito, A. (1981). Prestretch potentiation of human skeletal muscle during ballistic movement. Acta Physiological Scandinavian, 111, 135-140.

Bosco, C., Luhtanen, P., \& Komi, P. V. (1983). A simple method for measurement of mechanical power in jumping. European Journal of Applied Physiolohy and Occupational Physiology, 50(2), 273-82.

Brown, L., \& Weir, J. (2001). Procedures recommendation I: Accurate assessment of muscular strength and power. Journal of Exercise Physiology, 4, 1-21.

Cavagna, G. A. (2006). The landing-take-off asymmetry in human running. Journal of Experimental Biology, 209, 4051-4060.

Chin, E. R., Balnave, C. D., \& Allen, D. G. (1997). Role of intracellular calcium and metabolites in low-frequency fatigue of mouse skeletal muscle. American Journal Physiology, 272, 550-559.

Dowling, J., \& Vamos, L. (1993). Identification of kinetic and temporal factors related to vertical jump performance. Journal of Applied Biomechanics, 9, 95-110.

Fábrica, C. G., Alonso, R., Rey, A., Polero, P., \& Berreta, G. (2008). Explosive force in football association: Effects of competition and field location. International Journal of Performance Analysis in Sport, 8(2), 56-67.

Fisher, G. (2010). Anâlise da Mecânica da Corrida com e sem efeito da fadiga (Doctoral dissertation). UFRGS, Porto Alegre, RS, Brasil.

Green, H. J. (1997). Mechanisms of muscle fatigue in intense exercise. Journal of Sports Science, 15, 247-256.

Herzog, W. (2000). Cellular and molecular muscle mechanics. In W. Herzog (Ed.). Skeletal muscle mechanics: From mechanisms to function (pp.33-54). Chichester: John Wiley \& Sons, Ltd.

Hobara, H., Kanouse, K., \& Suzuki, I. S. (2007). Changes in muscle activity with increase in leg stiffness during hopping. Neuroscience Letters, 418, 55-59.

Horita, T., Komi, P. V., Nicol, C., \& Kyröláinen, H. (2002). Interaction between pre-landing activities and stiffness regulation of the knee joint musculoskeletal system in the drop jump: Implications to performance. European Journal of Applied Physiology, 88, 76-84.

Hortobagyi, T., Lambert, N. J., \& Kroll, W. P. (1991). Voluntary and reflex responses to fatigue with stretch-shortening exercise. Canadian Journal Sport Science, 16, 142-150.

Ingen Schenau, G. J. van. (1984). An alternative view of the concept of utilisation of elastic energy in human movement. Human Movement Science, 3, 301-336.

Isikawa, M., \& Komi, P. V. (2008). Muscle fascicle and tendon behavior during human locomotion revisited. Exercise Sport Science Review, 36, 193-199.

Kawakami, Y., \& Fukunaga, T. (2006). New insights into in vivo human skeletal muscle function. Exercise Sport Science Review, $34,6-21$.

Komi, P. V., \& Bosco, C. (1978). Utilization of stored elastic energy in leg extensor muscle by men and women. Medicine and Science in Sports, 10, 261-265.

Komi, P. V., Gollhofer, A. (1997). Stretch reflexes can have an important role in force enhancement during SSC exercise. Journal of Applied Biomechanics, 13, 451-460.

Kubo, K., Morimoto, M., Komuro, T., Tsunoda, N., Kanehisa, H., \& Fukunaga, T. (2007). Influences of tendon stiffness, joint stiffness, and electromyographic activity on jump performances using single joint. European Journal Applied Physiology, 99, 235-243.

Kuitunen, S. (2010). Muscle and joint stiffness regulation during normal and fatiguing stretch shortening cycle exercise. Studies in Sport, Physical Education and Health, 149. (Doctoral dissertation). University of Jyväskylä, Finland. 
Kyröläinen, H., Finni, T., Avela, J., \& Komi, P. V. (2003). Neuromuscular behavior of the triceps surae muscle tendon complex during running and jumping. International Journal Sports Medicine, 24, 153-155.

McMahon, T. A., \& Cheng, G. C. (1990). The mechanics of running: How does stiffness couple with speed. Journal of Biomechanics, 23, 65-78.

Moritani, T., Oddsson, L., \& Thorstensson, A. (1991). Electromiographic evidence of selective fatigue during the eccentric phase of stretch/shortening cycles in man. European Journal Applied Physiology, 60, 425-429.

Nicol, C., Avela, J., \& Komi, P. V. (2006). The Stretch-shortening cycle: A model study naturally occurring neuromuscular fatigue. Sports Medicine, 36(11), 977-999.

Rodacki, A. L., Fowler, N. E., \& Bennett, S. J. (2002). Vertical jump coordination: Fatigue effects. Medicine \& Science in Sports \& Exercise, 34(1), 105-116.

Strojnik, V., \& Komi, P. V. (1998). Neuromuscular fatigue after maximal stretch-shortening cycle exercise. Medicine Science Exercise, 32, 1314-1319.

Windhorst, U. (2007). Muscle propioceptive feedback and spinal networks. Brain Research Bulletin, 73,155-202.

Zhang, L. W., \& Zevrymer, W. (2001). Reflex and intrinsic changes induced by fatigue of human elbow extensor muscles. Journal of Neurophysiology, 86, 1086-1094.

Zib, G., \& Lidor, R. (2010). Vertical jump in female and male basketball players-A review of observational and experimental studies. Journal of Science and Medicine in Sport, 13(3), 332339.

\section{Author's note}

Carlos Gabriel Fábrica is with the Departamento de Biofísica (Unidad de Investigación en Biomecánica de la Locomoción Humana), Facultad de Medicina de Universidad de la República, Uruguay. cgfabrica@gmail.com

Paula V. González is with the Departamento de Rehabilitación y Medicina Física, Facultad de Medicina de Universidad de la República, Uruguay. pau.gonz.rod@gmail.com

Jefferson Fagundes Loss is with the Escola de Educação Física, Universidade Federal do Rio Grande Do Sul, Brasil.

\section{Correspondence to:}

C. Gabriel Fábrica

Departamento de Biofísica, Unidad de Investigación en Biomecánica de la Locomoción Humana

Facultad de Medicina

Universidad de la República

General Flores 2125 Montevideo, Uruguay

Phone: +59898267465

E-mail:cgfabrica@gmail.com

Manuscript received on September 22, 2011

Manuscript accepted on July 28, 2013

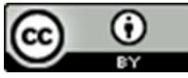

Motriz. Journal of Physical Education. UNESP, Rio Claro, SP, Brazil, eISSN: 1980-6574, is licenced under a Creative Commons License, Version 3.0. 